\title{
Implantação da estrada-parque e suas perspectivas para o campo do ecoturismo na região de Visconde de Mauá - RJ
}

Implementation of Park Road and its prospects for the field of ecotourism in the region of Visconde de Mauá - RJ

Amanda da Silva Cruz Gonçalves

Cláudio Leonel Salomão²

Diva Rezende Pereira ${ }^{3}$

Edna Maria Barbosa ${ }^{4}$

João Pedro Lima Pacheco da Silva ${ }^{5}$

Rafael Ângelo Fortunato ${ }^{6}$

\section{RESUMO}

Por este trabalho, busca-se o conhecimento das diferentes perspectivas dos principais atores sociais acerca da estrada-parque. Essa noção é importante para que as decisões sejam tomadas seguindo um planejamento participativo, por meio do qual é possível se chegar a uma diretriz comum que aponte para o respeito e para a tolerância no diálogo. A região de Visconde de Mauá passa por uma fase de conflitos em que alguns pensamentos são confrontantes entre segmentos da sociedade local. A estrada-parque foi pensada há mais de oito anos, porém se encontram muitas dificuldades para que se implante o projeto. Por meio de procedimentos

1 Graduada pela FATEC SENAC RIO em 2009.2 - Curso: Gestão de Turismo.

E-mail: amanda.goncalves.rj@hotmail.com

2 Graduado pela FATEC SENAC RIO em 2009.2 — Curso: Gestão de Turismo. E-mail: mu-anza@hotmail.com

3 Graduada pela FATEC SENAC RIO em 2009.2 - Curso: Gestão de Turismo. E-mail: divamaua@hotmail.com

4 Graduada pela FATEC SENAC RIO em 2009.2 — Curso: Gestão de Turismo. E-mail: edna@ednabarbosa.com

5 Graduado pela FATEC SENAC RIO em 2009.2 - Curso: Gestão de Turismo.

E-mail: joao.pedro.pacheco@hotmail.com.

6 Docente da FATEC SENAC RIO - Curso: Gestão de Turismo. Tutor do curso de Agenda 2I escolar: Formando elos de cidadania; Polo Paraty. Doutorando em Meio Ambiente — UERJ. E-mail: fortrafa@hotmail.com 
metodológicos, construiu-se o cenário atual e as perspectivas futuras ("pós-estrada"), por meio de entrevista semiestruturada e da aplicação da técnica de grupo focal. Tais metodologias qualitativas possibilitaram a realização de uma análise mais particular do caso. No decorrer do trabalho, após analisar a inter-relação da estrada-parque e suas perspectivas para o campo do ecoturismo, propõem-se medidas conciliatórias, auxiliando a promoção da sustentabilidade no local. Foi possível entender a ideia do planejamento participativo na atividade turística e a factível promoção do ecodesenvolvimento por meio da educação ambiental implicando o caminho para a sustentabilidade econômica e sociocultural na região.

Palavras-chave: estrada-parque, conflito, planejamento participativo, meio ambiente

\section{ABSTRACT}

This academic work pursues the knowledge of the different perspectives about the social actors around the Parkway. That Knowledge makes itself necessary for the takes of the major decisions, following a participatory planning, where the common guideline points to respect and tolerance in dialogs. The Visconde de Mauá region is facing a conflict stage, where some thoughts are conflicted between different parts of the local society. The Parkway has been thought for more than eight years, although there are many difficulties so it can be implanted. We have builted the present scene and the future perspectives ("after-Parkway") of the local society, through a semi-structured interview and the focal-group technique application. Those qualitative methodologies allowed a specific analyze of this case. Along this work, after analyze the interrelationship of the Parkway and the outlook for the field of tourism, we propose conciliatory measures, helping to promote sustainability and ethics in the place. It was possible to understand the idea of the participative planning in the ecotourism activity, and the possible promotion of the eco-development through the environmental education, implying in the way to the economic and socio-cultural sustainability of the region.

Key words: parkway, conflict, participative planning, local environment 


\section{INTRODUÇÃO}

A região de Visconde de Mauá - RJ, objeto de estudo deste trabalho, faz fronteira com o Parque Nacional de Itatiaia e encontra-se inserida em uma área de proteção ambiental, a APA da Mantiqueira, com características legais (legislações) específicas do SNUC — Sistema Nacional de Unidades de Conservação.

Objetiva-se analisar o cenário antes da construção da estrada-parque, que liga o trecho entre Capelinha/Visconde de Mauá - RJ-IG3 e Maromba/Ponte dos Cachorros — RJ-I5I, no distrito de Visconde Mauá - RJ, do ponto de vista dos atores sociais locais.

Para a realização do trabalho, partiu-se da premissa de que a estrada-parque contribuiria para a melhoria do ecoturismo na localidade, pois será construída seguindo os princípios da precaução da Declaração de Wingspread (I998) pela qual se sugere que "medidas de precaução devem ser tomadas, mesmo se algumas relações de causa e efeito não forem plenamente estabelecidas cientificamente".

Trabalha-se, pois, com os métodos de pesquisa participante, entrevistas semiestruturadas e grupo focal. Os dados obtidos revelam importantes informações para que se pense o planejamento do ecoturismo, tendo o princípio de precaução como referência.

\section{A região de Visconde de MaUá e suas características}

Visconde de Mauá é um distrito do município de Resende, localizado no estado do Rio de Janeiro, Brasil. A região compreende parte dos municípios de Resende (RJ), Itatiaia (RJ) e Bocaina (MG), e, em razão dessa peculiar geografia, atribuem-se à região conhecida como Visconde de Mauá as vilas de Mauá, Maringá, Maromba, seus diversos vales (Vale das Cruzes, Alcantilado, Pavão e Grama) e cadeias montanhosas. Localizado no alto da serra da Mantiqueira, cerca de I.40om acima do nível do mar, o vale que abriga a microbacia do rio Preto é um lugar que acolhe diversas quedas-d'água e tem sua natureza relativamente preservada. Faz fronteira com o Parque Nacional de Itatiaia, o sul de Minas Gerais e o do Rio de Janeiro, e o norte de São Paulo. 


\section{Figura 1: Mapa de Visconde de Mauá}

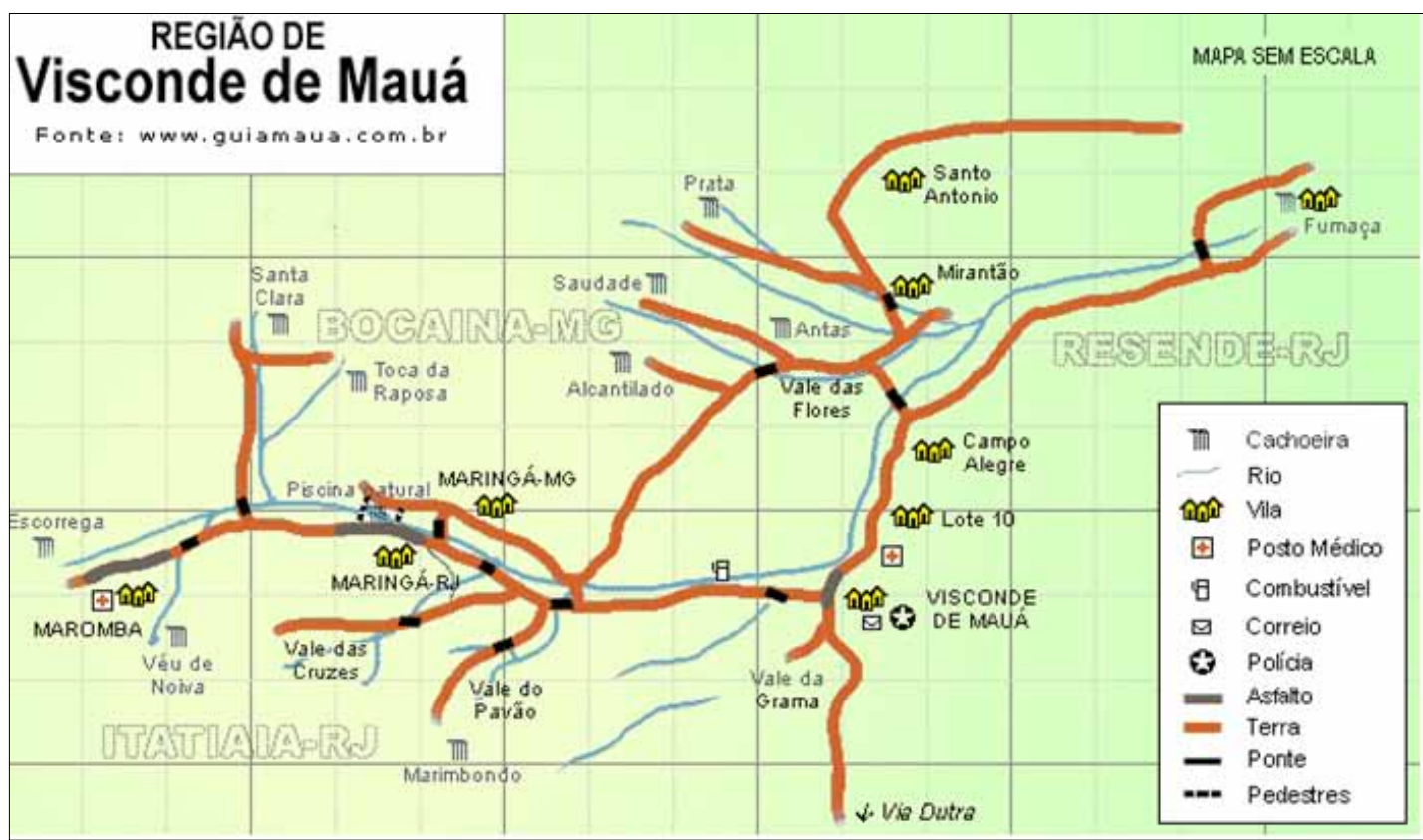

Fonte: www.guiamaua.com.br

Um dos principais acessos à região se faz por meio da rodovia Nova Dutra (BR-Iı6), na entrada do km 3II para Penedo e Mauá. Ressalte-se que a rodovia passou por diversas melhorias após sua privatização; assim, a qualidade (em termos de pista) aumentou e possibilitou a melhor apreciação da paisagem do vale do rio Paraíba e da serra da Mantiqueira. No sentido Rio-Mauá, existem apenas dois pedágios, enquanto que, no sentido São PauloMauá, se passa por quatro tarifas obrigatórias.

Hoje, Visconde de Mauá abriga, aproximadamente, seis mil pessoas. As três pequenas vilas que integram a região estão dispostas ao longo do rio Preto. A vila de Maringá, a segunda do trecho, oferece maior infraestrutura turística do que as outras, constituindo o centro comercial local. Maromba, por sua vez, dispõe de hospedagens de menor preço e é onde se concentra o maior número de cachoeiras e de outros atrativos naturais.

A comunidade local possui expectativas em relação ao desenvolvimento do turismo e, por causa das dificuldades de gestão pública (uma vez que as decisões afetam três estados), criou-se o Conselho Gestor da Microbacia do Alto do Rio Preto, que começou a funcionar em novembro de 2005 , formado por representantes do Poder Público, da iniciativa privada e da sociedade civil organizada. Parte do trabalho foi levantar dados na comunidade da região, relacionados com as principais demandas e necessidades básicas. Analisaram-se as informações obtidas que se transformaram, em seguida, em diretrizes, servindo de base para políticas públicas (decisões e ações do governo para solucionar 
problemas considerados pelo próprio governo e pelos cidadãos como prioritários ou de interesse público) propostas pelo Conselho às autoridades.

A estrada estará totalmente inserida na área de proteção ambiental da serra da Mantiqueira e preveem-se a construção de sistemas de drenagem, mirantes, passagens subterrâneas e aéreas para a observação da fauna local; a contenção de encostas; a implementação de sinalização turística; a melhoria da segurança e da educação ambiental; programas de restrição de tráfego de ônibus de excursões e caminhões de carga nos finais de semana e feriados, entre outras ações. Nos locais que serão pavimentados, estão sendo construídas três estações de tratamento de esgoto.

Nesse contexto, aprofundaram-se as pesquisas, a fim de investigar as perspectivas dos atores sociais locais em relação ao desenvolvimento da atividade turística na região de Visconde de Mauá - RJ, permeada pela construção da estrada.

\section{SUSTENTABILIDADE E ECOTURISMO}

Para Beni (2007, p.I27), "sustentabilidade pode ser entendida como o princípio estruturador de um processo de desenvolvimento centrado na equidade social, na eficiência econômica, na diversidade cultural, na proteção e conservação do meio ambiente".

No Brasil, a partir dos anos I990, as autoridades governamentais começaram a pensar no turismo como estratégia de desenvolvimento socioeconômico, incentivando a geração de emprego e de renda. Nos últimos anos, com a estabilidade da política econômica e com a crescente preocupação mundial com a sustentabilidade, os governantes têm criado políticas públicas de abrangência não só econômica como ambiental e sociocultural para o desenvolvimento do turismo sustentável, que pode ser definido como:

Aquele que é desenvolvido e mantido numa área (comunidade, ambiente) de maneira que, e em uma escala que se mantenha viável pelo maior tempo possível, não degrade ou altere o meio ambiente de que se usufrui (natural e cultural), não interferindo no desenvolvimento de outras atividades e processos, não degradando a qualidade de vida da população envolvida, mas, pelo contrário, servindo de base para uma diversificação da economia local (WALL, 1997, p. 38).

Durante anos, o turismo foi sendo incentivado e conduzido sem a preocupação com os impactos causados pela popularização da atividade que crescia de forma desordenada. Vale lembrar que tais impactos acabam causando sérios transtornos à sociedade e aos governantes, e refletem-se na exclusão social, na má distribuição de renda e em vários outros aspectos, os quais interferem negativamente no desenvolvimento dos países que passam a ter de solucionar problemas oriundos da atividade. Com a ideia de sustentabilidade surge, então, a necessidade de minimizar os impactos, reduzindo prejuízos futuros. 
Nesse cenário, a noção da capacidade de carga ganha relevância quando se cogita nas medidas de precaução ao construir uma estrada-parque, cuja proposta se tem instalado pelo País, pois se trata de uma visita a locais “frágeis". Segundo a OMT — Organização Mundial do Turismo, 2008 - assim se define a capacidade de carga total de um destino:

[...] o máximo uso que se pode fazer dele sem que causem efeitos negativos sobre seus próprios recursos biológicos, sem reduzir a satisfação dos visitantes ou sem que se produza efeito adverso sobre a sociedade receptora, a cultura ou a economia da área.

Já para o Ministério do Turismo brasileiro, 2008:
A capacidade de suporte é um processo de monitoramento das atividades turísticas e correlatas no meio ambiente físico, social e cultural e deve ser utilizada pelos gestores das destinações e/ou Unidades de Conservação como uma estratégia de manejo dos impactos da visitação.

Entende-se que, para um melhor diagnóstico ou mensuração da capacidade de suporte de uma região, é necessário analisar todo o contexto de uma forma mais aprofundada, levando-se em conta determinadas variáveis.

Não se pode esquecer de mencionar os indicadores capazes de esclarecer como a atividade turística pode impactar tanto positiva como negativamente em um destino. Com base no efeito que o turismo causa nos núcleos receptores ao gerar uma série de impactos, os autores Mathieson e Wall, I982; Bernaldéz I992; Western, I995; Lage e Milone, 200I destacam alguns indicadores de impacto:

\section{Efeitos econômicos positivos:}

$\rightarrow$ Geração de empregos.

$\rightarrow$ Diversificação da economia regional, com a criação de micro e pequenos negócios.

$\rightarrow$ Fixação da população no local, evitando o êxodo rural.

$\rightarrow$ Desenvolvimento e melhoria da infraestrutura de transportes, comunicações, saneamento, iluminação, etc.

\section{Efeitos econômicos negativos:}

$\rightarrow$ Instalação de segundas residências, prejudicando espaços e fontes de renda da população.

$\rightarrow$ Possíveis desvios dos recursos econômicos gerados na localidade pelo envio de divisas para fora (pagamento de salários de trabalhadores de outras cidades ou de produtos comprados fora do município, por exemplo).

$\rightarrow$ Aumento de preços de produtos em geral — inflação. 
$\rightarrow$ Especulação imobiliária.

\section{Efeitos socioculturais positivos:}

$\rightarrow$ Valorização da herança cultural, material e imaterial (festas, costumes, danças, culinária, artesanato).

$\rightarrow$ Orgulho étnico.

$\rightarrow$ Intercâmbio cultural.

$\rightarrow$ Conservação de locais históricos, preservando-se a arquitetura local.

$\rightarrow$ Resgate e perpetuação de atividades típicas da comunidade.

$\rightarrow$ Fortalecimento dos vínculos familiares e comunitários.

\section{Efeitos socioculturais negativos:}

$\rightarrow$ Descaracterização da vida social local.

$\rightarrow$ Relacionamento precário entre turistas e moradores, gerando tensões.

$\rightarrow$ Aumento de problemas sociais (uso de drogas, prostituição e violência).

$\rightarrow$ Degradação do patrimônio histórico e cultural.

\section{Efeitos ambientais positivos:}

$\rightarrow$ Diminuição do impacto sobre o patrimônio natural.

$\rightarrow$ Criação de alternativas de arrecadação para as Unidades de Conservação.

$\rightarrow$ Aumento da consciência da população local e dos turistas sobre a necessidade de proteção do meio ambiente.

$\rightarrow$ Criação de novas áreas protegidas.

$\rightarrow$ Conservação da biodiversidade.

$\rightarrow$ Melhoria da infraestrutura nas áreas naturais.

$\rightarrow$ Maior fiscalização por parte dos moradores, turistas e órgãos competentes.

\section{Efeitos ambientais negativos:}

$\rightarrow$ Poluições sonora, visual e auditiva.

$\rightarrow$ Introdução de espécies animais e vegetais exóticas.

$\rightarrow$ Prejuízos a espécies em seus hábitos alimentares, migratórios, etc. 
$\rightarrow$ Aumento na geração de lixo e de esgoto e problemas com saneamento básico.

$\rightarrow$ Alteração dos padrões hídricos, esgotamento de recursos minerais, exploração excessiva de recursos biológicos.

$\rightarrow$ Queima de combustíveis para aquecimento e iluminação.

Todos esses indicadores estabelecem relação intrínseca com a ideia de áreas de proteção ambiental, como a serra da Mantiqueira ou o Parque Nacional de Itatiaia; dessa forma, faz-se necessário entender as leis que regem o local para conhecer o cenário no qual a estrada-parque estará inserida.

Unidades de Conservação é o nome que se dá às áreas sujeitas a um uso ou uma ocupação especial, normalmente protegendo ecossistemas únicos e recursos ambientais de valor cênico e paisagístico. As UC's podem ser criadas pela união, pelos estados e pelos municípios. O Brasil teve a sua primeira Unidade de Conservação implantada em I937: o Parque Nacional de Itatiaia (RJ), criado com a finalidade de promover a pesquisa científica e a atividade turística. De acordo com Kinker (2002), o País retinha, no ano de 2002 , aproximadamente $8,13 \%$ de seu território legalmente protegido por essa forma de proteção (UC).

A Lei n.ffl 9.985, de I8 de julho de 2000, instituiu o Sistema Nacional de Unidades de Conservação da Natureza (SNUC), consolidando a estrutura relativa às UC's no Brasil e reunindo os instrumentos e normas existentes utilizados até então. Esse sistema estabelece critérios e normas para a criação, implantação e gestão das Unidades de Conservação. No capítulo II, art. 4.ffl, inciso XII, encontra-se, como um dos objetivos proposto pelo SNUC, "favorecer condições e promover a educação e interpretação ambiental, a recreação em contato com a natureza e o ecoturismo".

Para tanto, deve-se considerar a tipologia de Unidade de Conservação, pois nem todas permitem visitação pública para o lazer. É importante destacar que há dois principais grupos de UC's: as de Uso Sustentável e as de Proteção Integral dos Recursos Naturais (IBAMA/GTZ I997; MMA 2000).

Nas Unidades de Uso Sustentável, existe uma área denominada Área de Proteção Ambiental (APA), a qual receberá a estrada-parque da região de Visconde de Mauá. De acordo com o art. I5 das Unidades de Uso Sustentável:

A Área de Proteção Ambiental é uma área em geral extensa, com um certo grau de ocupação humana, dotada de atributos abióticos, bióticos, estéticos ou culturais especialmente importantes para a qualidade de vida e o bem-estar das populações humanas, e tem como objetivos básicos proteger a diversidade biológica, disciplinar o processo de ocupação e assegurar a sustentabilidade do uso dos recursos naturais. 
』I.ffl - A Área de Proteção Ambiental é constituída por terras públicas ou privadas.

』2.ffl - Respeitados os limites constitucionais, podem ser estabelecidas normas e restrições para a utilização de uma propriedade privada localizada em uma Área de Proteção Ambiental. 『3.ffl - As condições para a realização de pesquisa científica e visitação pública nas áreas sob domínio público serão estabelecidas pelo órgão gestor da unidade.

』4.ffl - Nas áreas sob propriedade privada, cabe ao proprietário estabelecer as condições para pesquisa e visitação pelo público, observadas as exigências e restrições legais.

『5.ffl - A Área de Proteção Ambiental disporá de um Conselho presidido pelo órgão responsável por sua administração e constituído por representantes dos órgãos públicos, de organizações da sociedade civil e da população residente, conforme se dispuser no regulamento desta Lei.

No mesmo contexto, enxerga-se a necessidade de conhecimento dessas leis que ajudam a proteger os locais previstos, assegurando o uso sustentável de cada unidade estudada. Considera-se também o Licenciamento Ambiental de suma importância, pois se trata de uma obrigação legal e prévia à instalação de qualquer empreendimento ou atividade potencialmente poluidora ou que promova a degradação do meio ambiente e possui, como uma de suas mais expressivas características, a participação social na tomada de decisão, por meio da realização de audiências públicas como parte do processo. Essa obrigação é compartilhada pelos órgãos estaduais de meio ambiente e pelo IBAMA, como partes integrantes do SISNAMA (Sistema Nacional de Meio Ambiente). É importante ressaltar que o IBAMA atua, principalmente, no licenciamento de grandes projetos de infraestrutura que envolvam impactos em mais de um estado e nas atividades do setor de petróleo e gás na plataforma continental.

As principais diretrizes para a execução do Licenciamento Ambiental estão expressas na Lei n.ffl 6.938/8I e nas Resoluções CONAMA n.ffl oor/86 e n.ffl 237/97. Além dessas, o Ministério do Meio Ambiente emitiu recentemente o Parecer n.ffl 312, que discorre sobre as competências estadual e federal para o licenciamento, tendo como fundamento a abrangência do impacto.

A Diretoria de Licenciamento Ambiental é o órgão do IBAMA responsável pela execução do licenciamento em nível federal e vem realizando esforços na qualificação e na reorganização do setor de licenciamento e trabalhando no sentido de disponibilizar aos empreendedores módulos de abertura de processo em formato on-line. Inicialmente o procedimento está disponibilizado para empreendimentos de usinas hidrelétricas, pequenas centrais hidrelétricas, linhas de transmissão e mineração. 
Sobre a estrada-parque, percebe-se que sua criação e gestão devam ser pensadas mediante o enquadramento em uma das categorias da lei que instituiu o SNUC (citada anteriormente). Como as Unidades de Conservação nasceram com propósitos e limitações, se a estrada estiver incluída em uma APA, como a estrada-parque de Visconde de Mauá, deve-se respeitar essas imposições da categoria.

\begin{abstract}
As estradas-parque são áreas onde a natureza é especialmente protegida, tendo em vista assegurar a apreciação da paisagem pelas pessoas que por ali trafegam em veículos ou passam a pé, inserindo a presença humana numa área natural de uma maneira compatível com a proteção à natureza e com a finalidade educativa das Unidades de Conservação (NETO, 2004, p. 68).
\end{abstract}

Para Moraes (1999), constrói-se a estrada-parque no intuito de promover o turismo, facilitar o tráfego ao longo de sua extensão, atrair os amantes da natureza e promover culturas e tradições locais, facultando o deslocamento dos visitantes em lugares de belezas exuberantes. Também serve para a promoção de opções econômicas de subsistência para os proprietários rurais e trabalhadores do campo, fomentando, por exemplo, o turismo rural. As estradas, de um modo geral, sempre causam impactos no ambiente em que estão inseridas, mas, se manejadas corretamente, servem como ferramenta de manipulação por grupos ligados aos poderes públicos ou privados (SORIANO, 2006). Assim, é preciso analisar atentamente os atores envolvidos e suas ações para a concretização do projeto de estrada, identificando, quando houver, o interesse de cada um dos participantes com relação ao ambiente e ao empreendimento em questão.

A primeira referência oficial sobre estradas-parque no Brasil é a do Plano do Sistema Nacional de Unidades de Conservação do Brasil, II Etapa de I982 (Instituto Brasileiro de Desenvolvimento Florestal - IBDF — e Fundação Brasileira para a Conservação da Natureza - FBCN). Nesse documento, apresenta-se somente o que se consideraria uma estrada-parque, assinalando-se, por meio de um quadro de resumo, os objetivos básicos dessa categoria.

É importante ressaltar que aqueles que praticam o ecoturismo, afirmam que "é uma forma de ecodesenvolvimento que representa um meio prático e eficaz de promover o crescimento socioeconômico em todos os países" (Cf. H. CEBALLOS-LASCURÁIN, Tourism, ecotourism and protected areas, I99I). No entanto, segundo Katrina Brandon (I993), em muitos casos, o ecoturismo provocou uma série de prejuízos nos locais praticados, como degradação ambiental, impactos negativos e dificuldades econômicas para a população local, em vez de oferecer os benefícios reais almejados. Encontra-se também, na literatura, alguns tópicos que explicam por que o ecoturismo não tem promovido o ecodesenvolvimento. A ausência de empenho e comprometimento político dos governos para 
"mobilizar recursos - humanos, financeiros, culturais e morais - que garantem a integração dos princípios ecológicos com o desenvolvimento econômico" (E. BOO; P. C. WEST e S. R. BRECHIN, I99I), o fato de o turismo e seus benefícios pertencerem a pessoas fora da região em questão (P. C. WEST; S. R. BRECHIN; M. WELLS e K. BRANDON, I992) e a falta de integração das necessidades e preferências locais no processo de planejamento (BRANDON, I993), por exemplo, são alguns desses tópicos.

Segue-se apresentando os resultados e enfatizando os significados da construção da estrada-parque para a região.

\section{Procedimentos metodológicos}

Para a confecção deste trabalho, em parte, empregaram-se entrevistas semiestruturadas em que se elaborou uma pergunta guia - O que você pensa da estrada-parque? - que foi respondida por 39 atores sociais envolvidos na atividade turística e possibilitou o surgimento de várias questões. Mattos (2005, p. 48) assevera: “A entrevista semiestruturada tem relativa flexibilidade. As questões não precisam seguir a ordem prevista no guia e poderão ser formuladas novas questões no decorrer da entrevista”. Utilizou-se, também, o método de pesquisa participante, que, segundo Minayo (2007; LAKATOS et al., I986), "se desenvolve com base na interação entre pesquisadores e membros das situações investigadas". Desenvolveu-se a pesquisa pela metodologia de grupo focal, em que se sugeriu aos II indivíduos participantes que comentassem sobre um cenário anterior e outro posterior à construção da estrada-parque. Com base no resultado, fez-se uma análise comparativa por aproximação dos dois cenários. Para Caplan (I990 apud DIAS, 2000), grupo focal é uma metodologia onde "pequenos grupos de pessoas são reunidos para avaliar conceitos ou identificar problemas". Investigou-se, ainda, a bibliografia e fizeram-se estudos de casos.

Concorda-se que, para fazer-se um diagnóstico real do cenário, é preciso repetir métodos. Ressalte-se que pesquisa "é a atividade científica pela qual se descobre a realidade” (DEMO, I985, p. 54). De acordo com Saloman (I999), a metodologia da pesquisa científica investiga profundamente um determinado assunto levando em conta seus vários ângulos e aspectos, dependendo dos fins a serem alcançados. 


\section{Análise e discussão dos resultados}

Para a apresentação dos resultados, identificaram-se algumas categorias de análise que permitiram entender como se expressam os conflitos presentes na construção da estradaparque, as quais se discutirão a seguir:

\section{Falta de infraestrutura na região}

Segundo se constata na revisão bibliográfica, a construção da estrada-parque pode ser um indicador de impacto positivo do turismo, mas se observam preocupações com a carência de estrutura básica, pois, segundo alguns entrevistados, "a falta de infraestrutura é mais urgente"; e, ainda, "por enquanto eu penso que aqui não tem estrutura para ter essa estrada; "no centro nos feriados temos confusão, imagina com a estrada"; "nessas circunstâncias eu sou contra [...] a estrutura feita não é suficiente”; "interessante, mas tem que vir com mais infraestrutura [...] tipo hospital que falta; banco, o pessoal fica louco que vem e não tem banco"; "tenho medo de vir muito de ônibus de excursão".

\section{Degradação do meio ambiente}

O aumento do fluxo turístico pode ser um fator negativo na conservação do meio ambiente, levando-se em conta o princípio da precaução e da capacidade de suporte. Segundo um dos moradores locais, "o estudo do impacto ambiental tem que ser feito de forma clara e seguindo as normas ambientais. O que me assusta nisso é a clientela que virá. Ela vai aumentar extremamente o fluxo do turista na região e isso vai destruir os nossos recursos naturais"; outros são ainda mais radicais: "a estrada-parque é a destruição de Mauá. O crescimento desordenado da região... não vem coisa boa, mas vem coisa ruim"; "tem que ser muito bem estruturada. A região não suporta um fluxo maior do que esse. Na situação atual, já é prejudicial. O impacto será muito grande"; "sou contra a estrada, e o asfalto vai descaracterizar o lugar".

\section{Aumento da violência}

O desenvolvimento pode trazer uma melhora na qualidade de vida da população local, porém deve envolver toda a comunidade, trazendo responsabilidades na gestão da atividade turística; contudo existe certa preocupação por parte da população local relacionada com a violência e expressa em frases, como "o lado ruim é que vai 'cidadificar' os delinqüentes / vagabundos vão passar a frequentar o local”; "a facilidade de acesso vai trazer a violência urbana para cá"; "não temos segurança e não existe infraestrutura, vem coisa boa, mas vem coisa ruim". 


\section{Melhorias para Visconde de Mauá - RJ}

Apesar de uma corrente trazer à tona os impactos da construção da estrada-parque, outra chama a atenção para sua contribuição por meio do aumento de oportunidades para geração de emprego e renda. Tal posicionamento torna-se explícito em falas do tipo: "eu sou totalmente a favor, já que fui moradora, e eu acho que, para o desenvolvimento local, é fundamental"; "acho que vai ser um divisor de águas, acho que vai ser bom, e o governo do estado está oferecendo suporte para articular os respectivos planos diretores. É um fechamento de um ciclo. Queremos a estrada"; "sou a favor da estrada. Vai trazer gente e a cidade está falindo. Ecologicamente mais correto ter uma estrada-parque"; "A construção da estrada poderá conter a assoreamento das encostas, preservando-a da degradação natural causada pelas chuvas"; "Acho que vai trazer benefícios para a cidade. Você pode ter asfalto, iluminação e ter educação ambiental. Tem que fazer um trabalho de conscientização"; "É o novo estado do Rio de Janeiro. O único lugar que a Mata Atlântica é existente. A estrada vai preservar o local".

\section{Controle e capacidade de carga}

Nos discursos dos entrevistados, a questão relacionada com a capacidade de carga, discutida na revisão bibliográfica, aparece, de forma indireta, em certas expressões: "eu sou a favor. Eu sou a favor que criem rotas alternativas, pois o fluxo aqui já está complicado"; "no centro nos feriados temos confusão, imagina com a estrada”; “a estradaparque é a destruição de Mauá. O crescimento desordenado da região não tem fiscalização".
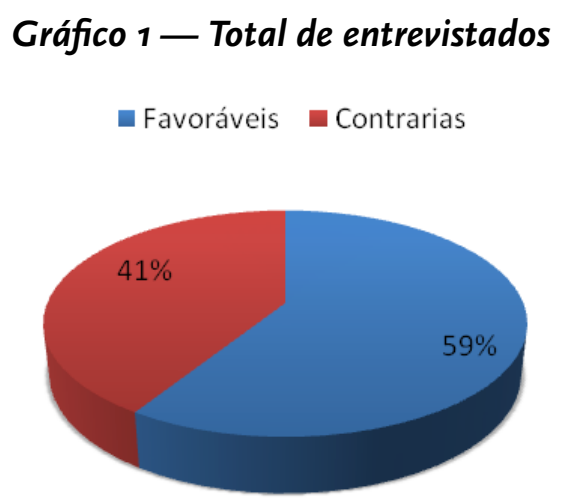

Elencadas as categorias, pensa-se em mensurar quantitativamente os atores sociais favoráveis e os contrários à construção da estrada-parque. Os resultados podem ser usados em uma série de análises. Uma das propostas foi a de comparar as respostas das 39 pessoas entrevistadas; diante disso, obteve-se um resultado revelador: 59\% são favoráveis, e 4I\%, contrários à implantação da estada; o que revela que, apesar dos conflitos travados a respeito do assunto, a maioria dos entrevistados aprova a concretização do projeto, mas faz diferentes ressalvas sobre o tema que são muito importantes quando se cogita em perseguir o princípio de precaução. 
Para aprimorar a qualidade e a eficiência dos resultados e entender melhor as ressalvas feitas pela população local, utilizou-se também outros tipos de provocações por meio da metodologia de grupo focal.

Houve uma reunião, com a presença de II moradores locais, em que se propôs uma dinâmica: todos escreveriam uma frase, cujo tema provocava uma reflexão sobre o cenário atual de Visconde e Mauá, e outra sobre como pensavam o cenário após a construção da estrada-parque. Por esse segundo método de pesquisa, extraíram-se dados que podem representar indicadores de impacto, positivos e negativos, segundo a percepção dos moradores locais, assim como ocorreu por meio das entrevistas. Com os resultados, construiuse uma tabela, pela qual se comparam as respostas que mais se aproximaram; com isso, busca-se entrever de que forma os impactos preocupam os atores sociais locais.

1. ${ }^{a}$ Etapa - Cenário atual

Dificuldade de acesso

Multiplicidade cultural

Pluralidade forte

Política segmentada

Falta de oportunidade para os jovens

Lugar tranquilo socialmente

Crescimento populacional

A localidade cresce populacionalmente

A estrada passou a ser uma necessidade

Abandono da região

Falta de realização de eventos em geral

Grande inconsciência ambiental, todas as idades, empresários e trabalhadores

Fragilidade cultural

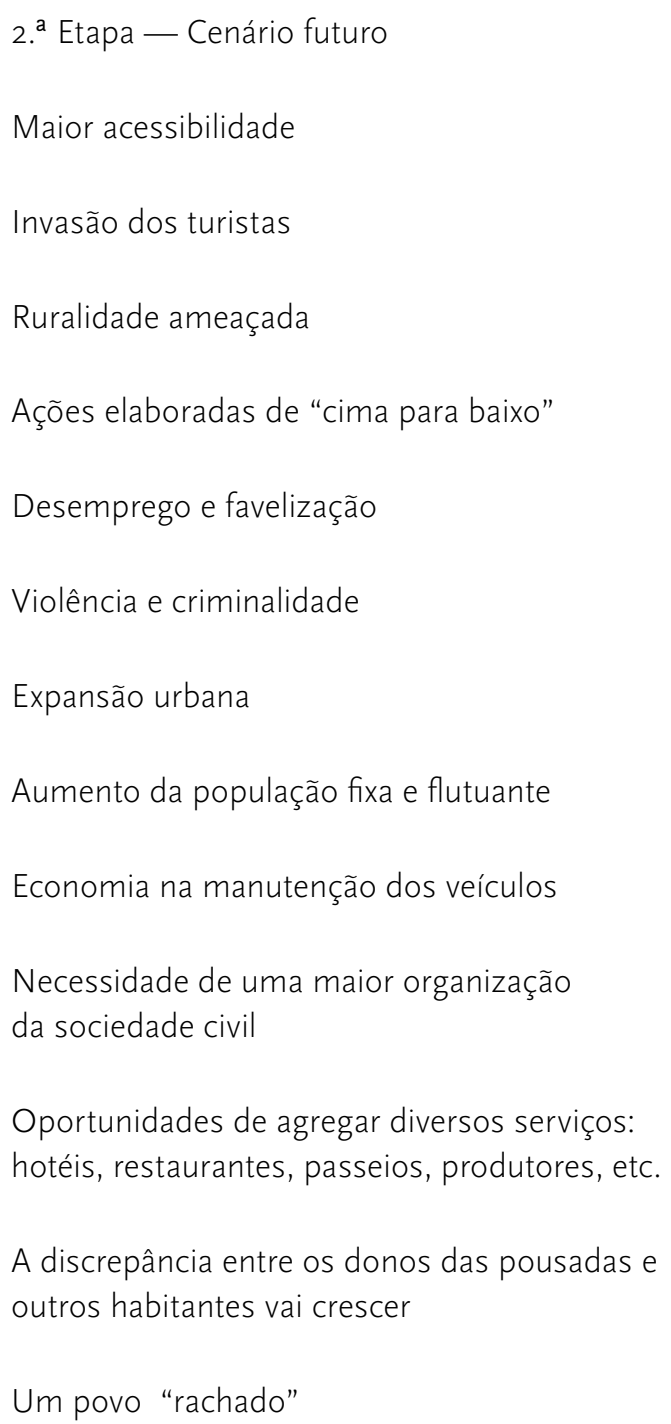




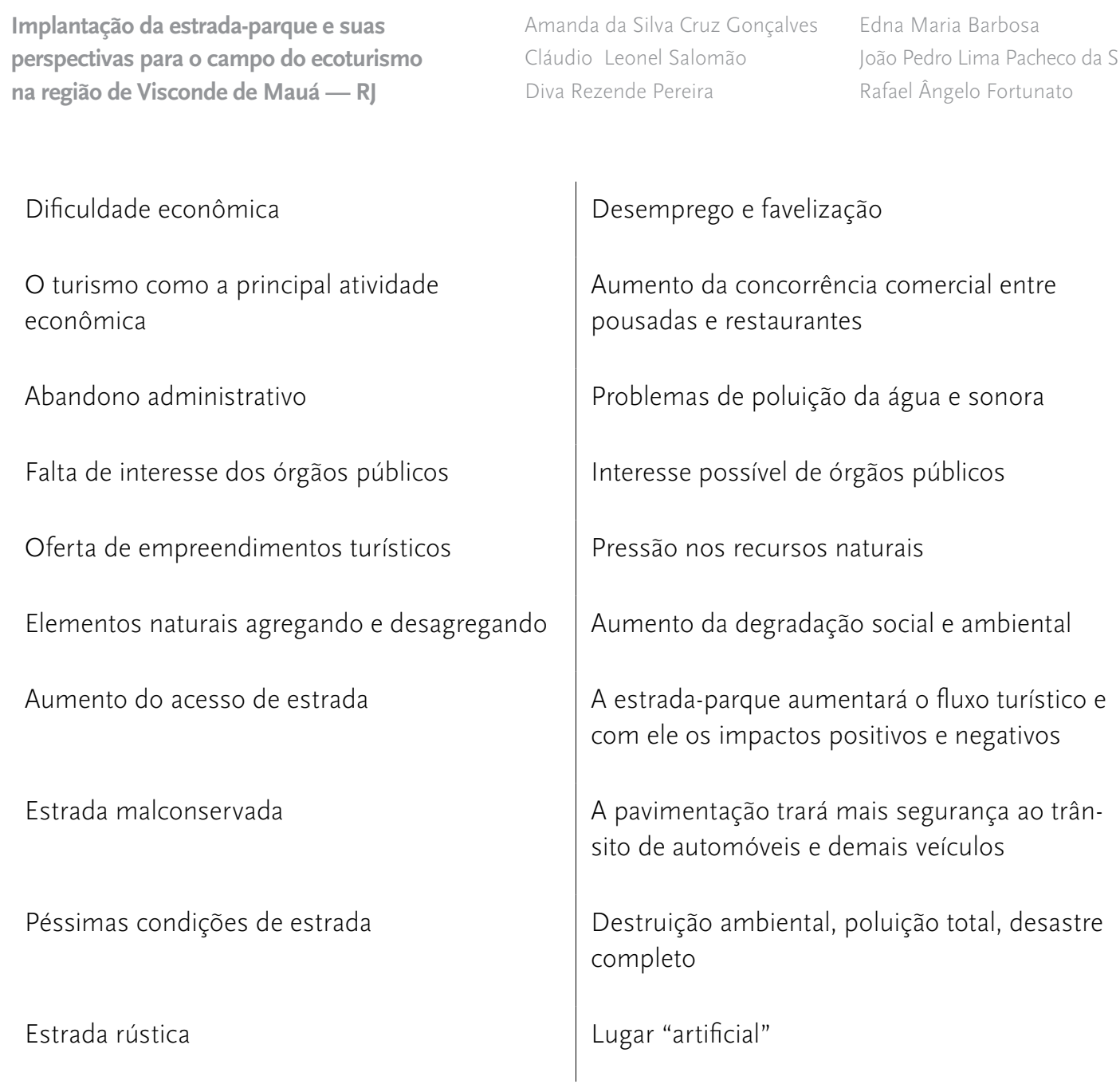

Alguns aspectos apontados no cenário futuro, como "invasão dos turistas" e "aumento da degradação social e ambiental", aparecem como indicadores de impactos negativos; enquanto que "maior acessibilidade" e "oportunidades de agregar diversos serviços: hotéis, restaurantes, passeios, produtores, etc." podem ser considerados impactos positivos.

Por meio dos resultados apontados nas pesquisas, observa-se que os impactos trazidos pela "invasão dos turistas" tendem, de fato, a comprometer a identidade do lugar; e, para que isso seja minimizado, é preciso que exista um planejamento turístico participativo pelo qual os moradores, a sociedade civil organizada e os órgãos públicos possam convergir para o bem comum. 


\section{CONSIDERAÇÕES FINAIS}

A região de Visconde de Mauá, já está inserida na atividade turística. Há, espalhados por toda a região, muitos hotéis e pousadas fazendo do turismo uma das atividades locais mais lucrativas. A construção de uma estrada-parque entranhada nos três principais distritos — Maromba, Maringá e Mauá -, segundo a população local, impactará a localidade.

Esta presente situação permite refletir sobre as diversas perspectivas dos atores sociais locais, levando-se em conta as dimensões ecológica, econômica e sociocultural. Também propicia a análise da prática do ecoturismo em áreas de proteção ambiental, investigando-se os conflitos locais existentes com o intuito de buscarem-se soluções que minimizem impactos e contribuam de alguma forma para a construção de uma sociedade sustentável.

Conseguiu-se extrair os aspectos mais preocupantes do ponto de vista da população local, como a preocupação com os impactos ecológicos e socioculturais. A sociedade local, em sua maioria, ainda é favorável à implantação da estrada, porém com muitas ressalvas que, quando ouvidas, podem contribuir para o processo de construção da estrada-parque sob o princípio da precaução (Declaração de Wingspread,I998), discutido no início deste artigo.

Diante das reflexões realizadas, a principal proposta para a atividade turística é a implantação do ecoturismo de base comunitária em algumas regiões de Visconde de Mauá, tendo em vista que uma das autoras do trabalho é moradora da localidade. Acredita-se que, partindo da identificação dos Arranjos Produtivos Locais (APL's), ter-se-á a possibilidade de identificar os segmentos com maior potencial para ajudar a promover o Desenvolvimento Local Integrado e Sustentável (DLIS), podendo-se, assim, maximizar os benefícios do ecoturismo na localidade.

O planejamento e a disseminação do ecoturismo de base comunitária possibilitam, em longo prazo, consolidar a região como um destino ecoturístico sustentável, um status muito almejado no contexto atual.

Beni (2006) comenta sobre a falta de visão sistêmica e holística que impediu que o turismo no Brasil alcançasse patamares de desenvolvimento mais expressivos. A educação ambiental e a valorização da identidade local ampliam essa visão e instrumentalizam os diversos personagens para que a atividade turística seja fomentadora do exercício da cidadania. 


\section{REFERÊNCIAS}

Bartolo, R.; Delaramo, m.; Baldin, L. Turismo e sustentabilidade do estado do Rio de Janeiro.

Rio de Janeiro: FAPERJ, 2005 .

BENI, M.C. Análise estrutural do turismo. São Paulo: SENAC, 2007.

BRECHIN, S. R. Evaluation of organizational performance in mountain forestry programmes.

In: Forests in sustainable mountain development: a state of knowledge report for 2000.

New York: CABI, 2000.

Planting trees in the developing world: sociology of international organizations.

Baltimore: Johns Hopkins University Press, 2000.

CAPLAN, s. Using focus group methodology for ergonomic design. Ergonomics, [local?] vol.

33, n.ffl 5, p. 527-533, I990.

De paula, J. Desenvolvimento local. Sebrae nacional, São Paulo, 2008.

DIAS, R. Turismo sustentável e meio ambiente, São Paulo, Atlas, 2003.

FORTUNATO, R. Representação social da educação ambiental e sua contribuição ao turismo.

Revista Brasileira de Ecoturismo, São Paulo, v. 2, n.ffl 2, p. I60-I87, 2009.

FrAnco, A. Por que precisamos de desenvolvimento local integrado e sustentável. São

Paulo: Instituto de Política/ Millennium, 2000.

GASTAL, S.; MOESh, M. Turismo, políticas públicas e cidadania. São Paulo, Aleph, 2007.

IBAma/GTZ. Roteiro metodológico para planejamento de Unidades de Conservação de Uso

Direito. Brasília: IBAMA/GTZ, I996.

KINKER, S. Ecoturismo e conservação da natureza em parques nacionais. Campinas-SP,

Papirus, 2002.

LaKatos, E. M.; marconi, M. A. Fundamentos de metodologia científica. São Paulo, Atlas, I985. LINDBERG. K.; HAWKINS, D. E. Ecoturismo: um guia para planejamento e gestão. São Paulo,

SENAC, 2002.

MACHADO, A. Ecoturismo: um produto viável - experiência do Rio Grande do Sul. São

Paulo, SENAC, 2005.

MATTOS, P.; LINCOLN, C. L. A entrevista não estruturada como forma de conversação: razões e sugestões para sua análise. Revista de Administração Pública, São Paulo, v. 39, n.ffl 4, p. 823-847, jul.-ago. 2005 .

MITRAUD, s. (org.). Manual de ecoturismo de base comunitária. Brasília: WWF Brasil, 2003. MOLINA, E. s. Turismo e ecologia. São Paulo: EDUSC, 200 I.

омт. Código mundial de ética do turismo. Santiago do Chile: омт, I999. Pellegrini filho, A. Dicionário enciclopédico de ecologia e turismo. São Paulo, Manole, 2000. 
RusChmann, D. M. Turismo e planejamento sustentável: a proteção do meio ambiente. São

Paulo: Papirus, I997.

SACHS, I. Caminhos para o desenvolvimento sustentável. Rio de Janeiro: Garamond, 2002. SAlomon, D.v. Como fazer uma monografia. São Paulo: Martins Fontes, I999. SNPT/DEAOT/CGS. Manual de ecoturismo: orientações básicas. Brasília: MTur, 2008. SORIANO, A. J. S. Estrada-Parque: proposta para uma definição. UNESP - Instituto de Geociências e Ciências Exatas - Campus Rio Claro, São Paulo, 2006. SWARBROOKE, J. Turismo sustentável: conceitos e impactos ambientais. São Paulo: Aleph, 2000. TOMAR, M. S. A Entrevista semiestruturada. São Paulo: Universidade Aberta, 2007/2009.

[n.ffl de p.?]. Tese (Mestrado) em Supervisão Pedagógica, Universidade Aberta, São Paulo, Edição 2007/2009. vignati, F. Gestão de destinos turísticos. Rio de Janeiro: SENAC, 2008.

Wells, M.; BRANDON, K. People and parks: Linking protected area management with local communities. Washington DC: World Bank WWF/usAID, I992.

\section{Sites de internet:}

Disponível em: http://www.sosmatatlantica.org.br/index.php?section=project\&action=list Projects. Acesso em 5 ago. 2009.

Disponível em: http://search.scielo.org/?q=Estrada\%2oparque\&where=ORG. Acesso em: IO ago. 2009 .

Disponível em: http://www.turismo.gov.br/turismo/programas_acoes/regionalizacao_ turismo/estruturacao_segmentos/ecoturismo.html. Acesso em: 2 ago. 2009.

Disponível em: http://www.mma.gov.br/sitio/. Acesso em: I2 out. 2009.

Disponível em: http://www.ecocentro.org/. Acesso em: I5 nov. 2009.

Disponível em: http://viajeaqui.abril.com.br/. Acesso em: 9 set. 2009.

Disponível em: http://oglobo.globo.com/viagem/. Acesso em: 9 set. 2009.

Disponível em: http://www.administradores.com.br/. Acesso em: 3 out. 2009.

Disponível em: http://www.ecobrasil.org.br/. Acesso em: 3 out. 2009.

Disponível em: http://www.institutoverdevida.org.br/. Acesso em: I8 nov. 2009.

Disponível em: http://p.download.uol.com.br/guiamaua/dt/Livro_Ecoturismo.pdf. Acesso em: I8 nov. 2009. 